European Association for the

Development of Renewable Energies, Environment and Power Quality (EA4EPQ)
International Conference on Renewable Energies and Power Quality (ICREPQ'11)

Las Palmas de Gran Canaria (Spain), 13th to 15th April, 2011

\title{
The effect of surface impurities on photovoltaic panels
}

\author{
L. Dorobantu, M.O. Popescu, Cl. Popescu, A. Craciunescu \\ Electrical Engineering Faculty \\ POLITEHNICA University of Bucharest \\ 313 Independentei, 060042 Bucharest, Romania, Tel/Fax : +040 213181003 \\ loredana.dorobantu@upb.ro; mo_popescu@ rectorat.pub.ro; claudia.popescu@upb.ro
}

\begin{abstract}
This paper deals with the surface impurities that occur onto operating solar cells, a widespread problem. The depositions on the photovoltaic cells, represented by dust and dirt which appear inevitably, lead to deterioration over time or to the decrease of efficiency of the panels that contain the affected cells, and as a result there are losses that appear in the system. Some local depositions create shady areas, causing significant overheating which is experimentally highlighted..
\end{abstract}

\section{Key words}

renewable energy, solar cells efficiency, the effect of the impurities, thermo-vision, model.

\section{Introduction}

The depositions left by birds, pollution and the dust caused by traffic or from the agricultural activities accumulate rapidly and can reduce the efficiency of the photovoltaic cells by $20 \%$ during a dry summer. Other factors such as panel orientation or panel surface material can contribute to the deposition of the impurities. The rules for maintaining the photovoltaic panels are simple, maintaining their surface permanently clean being an important aspect. The deposits left by birds or the fallen leaves should be often removed, because the cells overheat due to the energy of the other covered cells around them, this situation leading to a permanent or long-term failure. The fact that panels should not be shaded is to be taken into account, because the slightest shadow of a panel portion may lead to a decrease in yield by $50 \%$. [1]

To illustrate the statements above, there were made measurements using the thermo-vision camera TI20, Fluke product, and simultaneously simulations using Comsol
Multiphysics software, in order to observe the behavior of the covered cell during the operation.

The main purpose of this paper is outlining the losses that occur in the solar cells due to the depositions and to the shadings, as a result of their heating.

\section{The effects of the deposition on the solar cells surface - experimental determination}

The experimental determinations were made on polycrystalline panels Schott Solar - AES-275-DG-FT located within the Faculty of Electrical Engineering, Politehnica University of Bucharest.

Using the thermo-vision camera it was noted that any deposit or defect in the structure of the panel leads to a heating of the affected area compared with the rest of the panel (Fig.1). Thus, there have been taken some parts of solar cells for study that contained depositions left by birds, which can cause both temporary defects by their mere presence on the surface of the photosensitive cell and permanent defects on the structure of the affected area. The images below, figures 1 and 2, illustrate the best the temperature difference existing between the covered areas and clean areas. In the image captured with the thermovision camera it can be clearly observed that the covered surface has the temperature increase up to $10^{\circ} \mathrm{C}$, namely from the normal temperature of the panel $\left(27.8^{\circ} \mathrm{C}\right)$ with no deposits, to the temperature of $37.5^{\circ} \mathrm{C}$, recorded on the dirty area. The temperature variation on the surface of the panel is presented also by the temperature histogram shown by the camera (Fig. 3). Where it can be easily noticed that the last 
value recorded of the temperature is $37.5{ }^{\circ} \mathrm{C}$, which occurs in areas where deposits were dense.

This first case, where we have a dense deposit (more consistent), can be compared to a permanent fault on the panel surface because removing it without human intervention is more difficult, thus local heating may occur, until the complete disappearance of this additional layer.

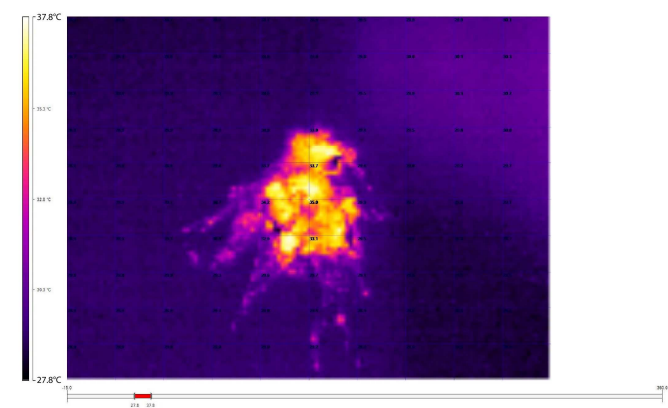

Fig. 1. Image of a deposition on the panel surface captured with the thermo-vision camera

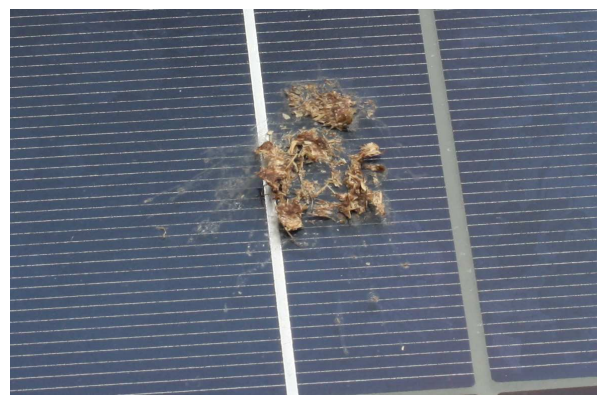

Fig. 2. The real image of the deposition on the panel surface

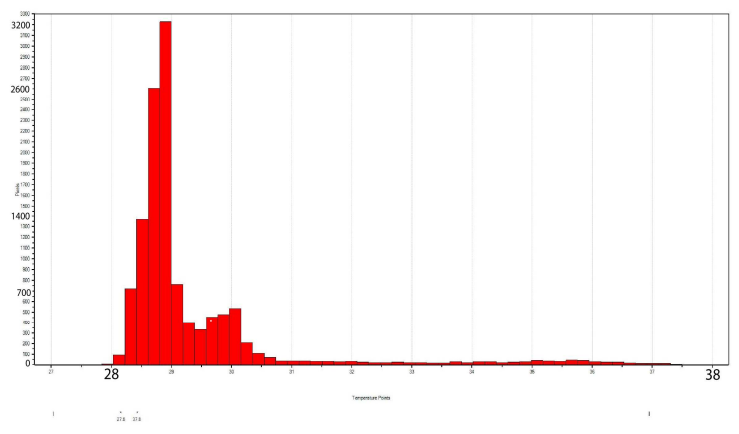

Fig. 3. The histogram of the picture taken with the thermo-vision camera for the area of the panel that contains the deposition

The measurements made, show that panel losses caused by heating are easily perceptible due to the thermo-vision, proving the fact that any coverage of a cell inevitably leads to its heating and thus the occurrence of losses, reflected in lower electricity production.
For a better comparison, the thermo-vision camera images of the panels were made on the clean surface (Fig. 4). In all the pictures where the images taken with the thermo-vision camera appear, the numbers from the network shown by the camera have an equivalent in histograms.

The most obvious difference shows between the ends of the scale of the histogram (Fig. 6). In this case the difference between the two values does not exceed $2{ }^{\circ} \mathrm{C}$ due to the orientation of the panel. So, at the bottom of the panel we have a slightly higher temperature (about $0.5^{\circ} \mathrm{C}$ ) due to the temperature influence of the mounting surface of the panel.

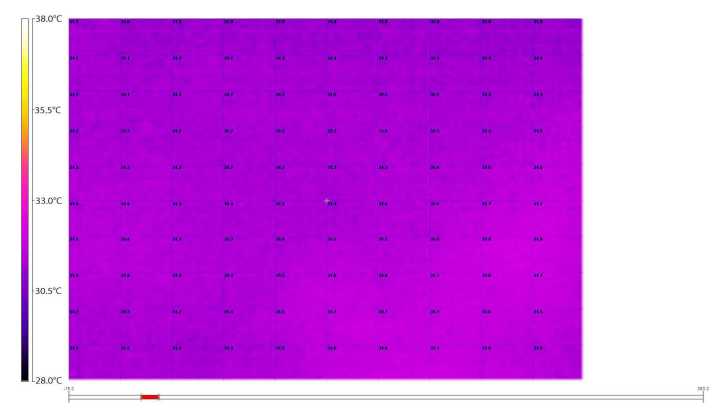

Fig. 4. Image of the first clean panel captured with the thermo-vision camera

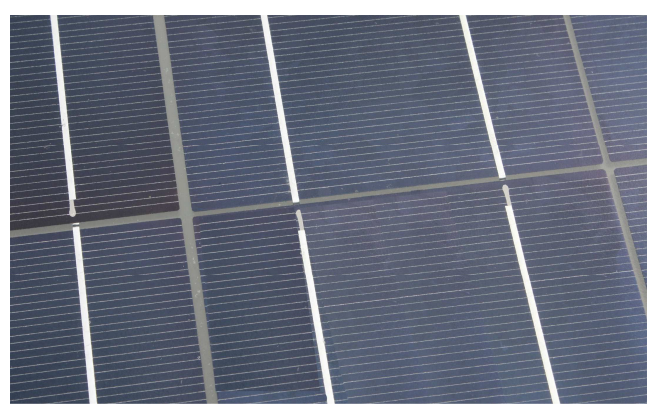

Fig. 5. Real image of the first clean panel

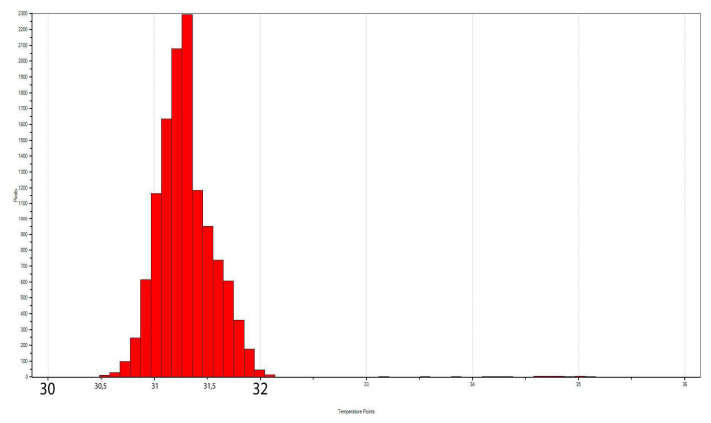

Fig. 6. The histogram of the picture taken with the thermo-vision camera for a clean area of the first panel 
Most often, the mounting surfaces of the solar panels tend to reach higher temperatures, so there is inevitably a slight increase in temperature in the cells nearby.

In figure 7 it is presented the case of a less consistent deposit compared to the first case (Fig.1), which creates a partial defect in turn, and which does not affect very much, according to the histogram in figure 9 .

Meanwhile, the temperature differences between affected areas and the clean coating of the panel does not exceed $5^{\circ} \mathrm{C}$. However even if the losses caused by the warming are smaller, they are present. This is proved by the mere presence of the hottest points on the surface of the panel.

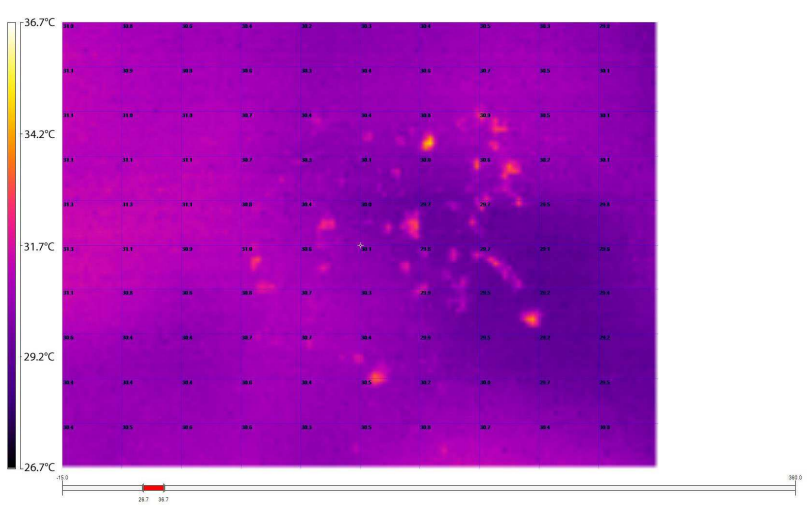

Fig.7. Image of less consistent deposit on a photovoltaic panel taken with a thermo-vision camera

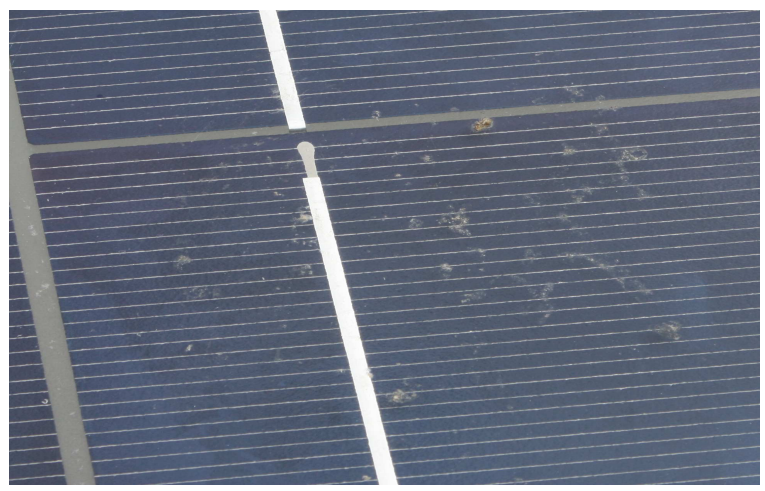

Fig.8 Real image of a less consistent deposit on a photovoltaic panel

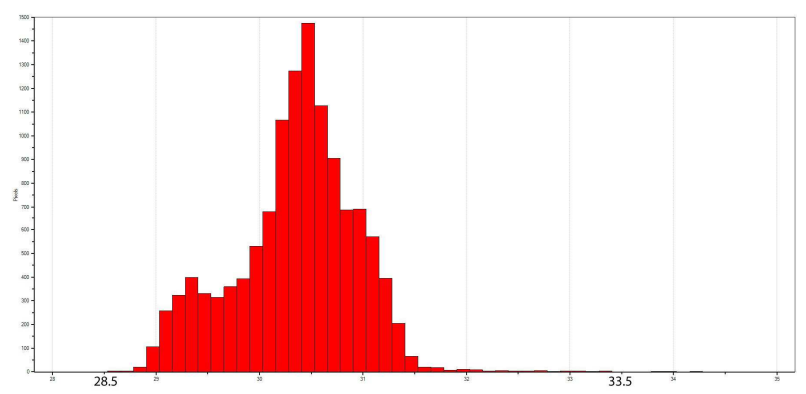

Fig.9 Histogram with less consistent deposition
Issues related to the temperature difference are determined not only by the presence of supplementary layers that do not allow local illumination of the cell. Temperature differences appear on clean surface panels and do not exceed $2^{\circ} \mathrm{C}$, but they are due to certain factors of heterogeneity in the structure of the panel or the position that panels have in the system.

In figure 10, we have a picture of another clean photovoltaic panel taken with the thermo-vision camera. As in figure 4, on this panel do not appear more different temperature points.

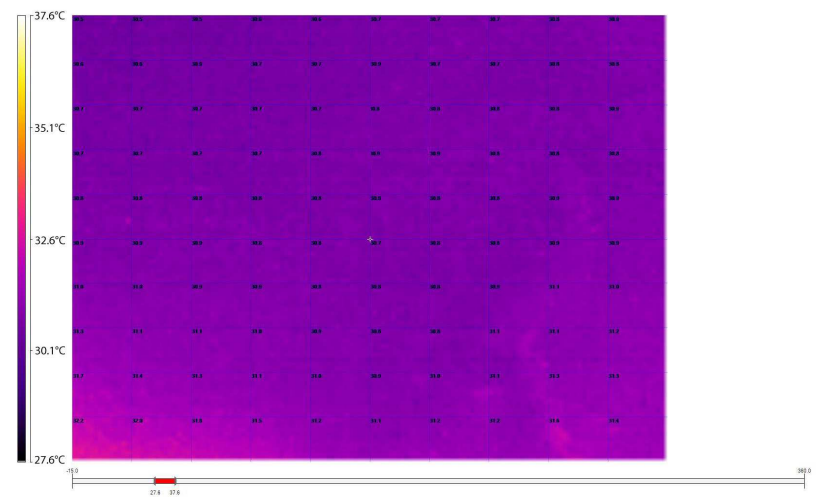

Fig.10 Image taken with a thermo-vision camera for the second clean panel

Carefully following the data provided by the histograms (Fig. 6, Fig.11), the registration of small deviations from the average temperature in the panel which is somewhere around $31^{\circ} \mathrm{C}$ is observed.

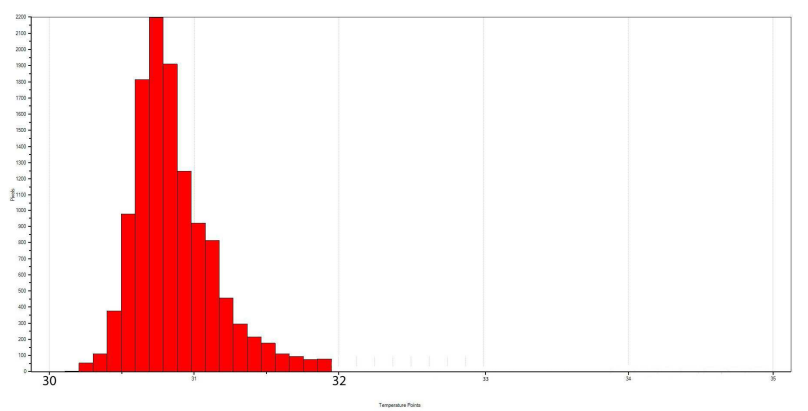

Fig.11 Histogram of the second clean panel

For a better comparison, we have introduced in the table below (Table I) all the data of interest for all four cases under discussion. 


Table I
\begin{tabular}{|c|c|c|c|}
\hline Deposit Type & $\begin{array}{c}\text { Panel } \\
\text { medium } \\
\text { temperature } \\
{\left[{ }^{\circ} \mathbf{C}\right]}\end{array}$ & $\begin{array}{c}\text { Panel highest } \\
\text { temperature } \\
{\left[{ }^{\circ} \mathbf{C}\right]}\end{array}$ & $\begin{array}{c}\text { Tmax and } \\
\text { Tmin } \\
\text { difference } \\
{\left[{ }^{\circ} \mathbf{C}\right]}\end{array}$ \\
\hline $\begin{array}{c}1^{\text {st }} \text { Clean panel } \\
\text { (Fig.4) }\end{array}$ & 31.25 & 32.10 & 1.60 \\
\hline $\begin{array}{c}2^{\text {nd }} \text { Clean panel } \\
\text { (Fig.11) }\end{array}$ & 30.75 & 31.90 & 1.70 \\
\hline $\begin{array}{c}\text { Low deposit } \\
\text { panel (Fig.7) }\end{array}$ & 30.50 & 33.40 & 4.90 \\
\hline $\begin{array}{c}\text { Panel with } \\
\text { consistent } \\
\text { deposit (Fig.1) }\end{array}$ & 29.00 & 37.50 & 9.50 \\
\hline
\end{tabular}

Following the basic principles of solar cell function, it can be said that the most poorly lighted cell determines the current through all other cells in series. It is a similar effect prodused by the action of a force in a certain section of the hose, through which the water flows, resulting into a smaller quantity of water after surpassing that section. [3]

\section{Simulation of deposition on the surface of solar cells in Comsol Multiphysics}

To get a clear picture on the negative effects of depositions on photosensitive surfaces, simulation of a solar cell was realized in the software environment Comsol Multiphysics. A part of the cell area was covered by an opaque layer, creating thus an artificial surface defect. The model created was bidimensional (2D), in order to monitor the evolution of the temperature of the panel in cross-section view.

The simulation was performed using a silicon solar cell which has a network of 2546 nodes and 15,705 freedom degrees. [7]

To solve the problem, existing modules were used in Comsol Multiphysics: Conductive Media and Electrostatics. In figure 12, the temperature evolution of a cell having an artificially imposed defect is shown in cross section.

The opaque layer from the simulated model corresponds to the deposition on the photovoltaic cell, causing warmer areas around it. Thus, the shadowed part of the cell determines power drops and can vary depending on how the deposit is located on photovoltaic cells. The power loss increases considerably if the deposit affects many cells grouped in parallel, the effect being an introduction of a large impedance, simulating an open circuit. [3]

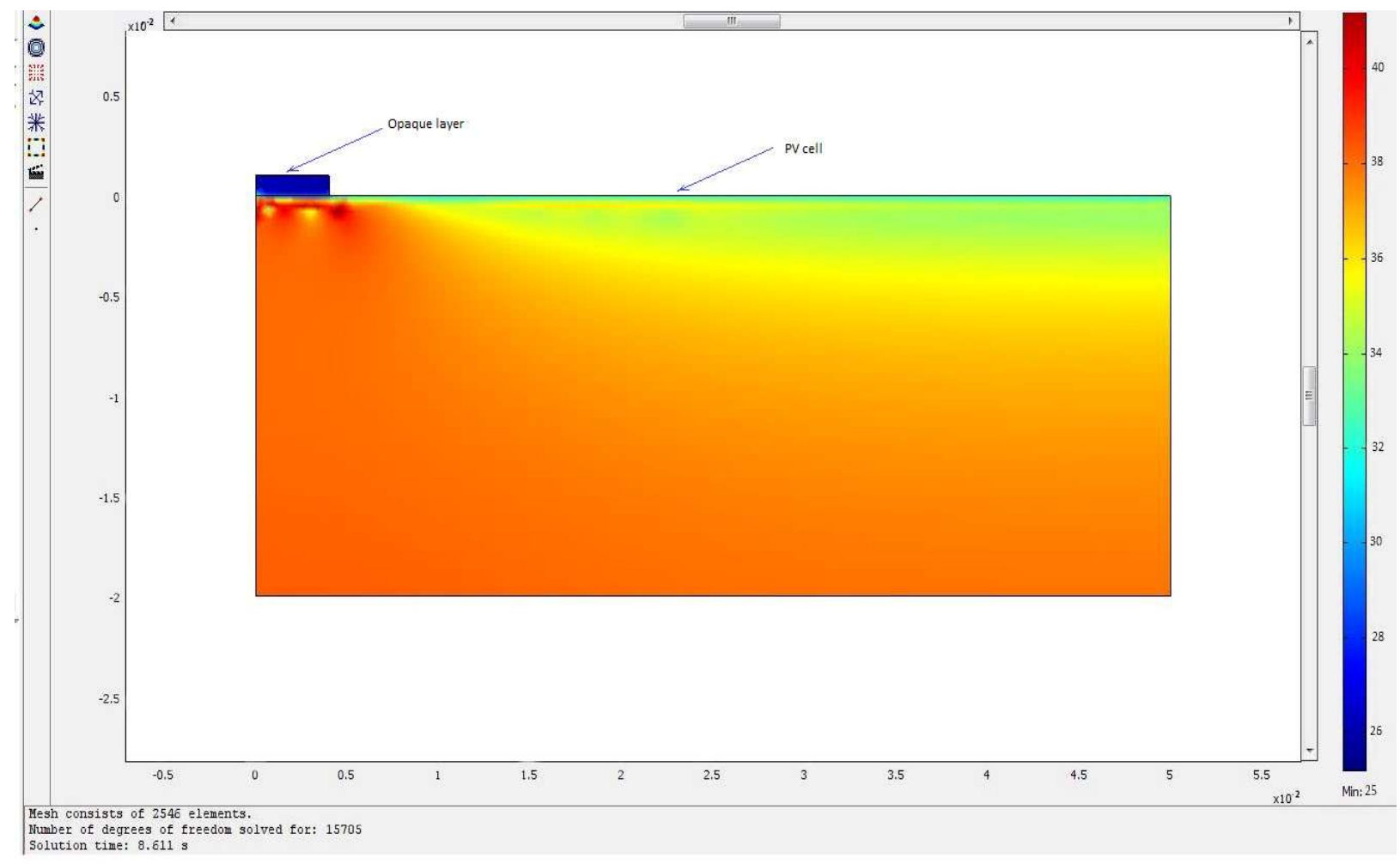

Fig.12. The conduction of the heat within the covered cell (cross section)- model realized in Comsol Multiphysics 
Values of the temperature are very close to those measured with the thermo-vision camera, after the simulation. Next to the deposit, the highest values are reached, which finally affect the entire cell, as the simulation shows. These increased values of the impedance of the cells from the deposit area consist of Joule losses for the entire panel.

\section{Solution}

To minimize the losses caused by the deposition on the panels surface, an efficient solution is the self-cleaning technology. Extensive research has been done in this direction in order to find a way to clean accumulated dirt, especially dust and sand particles, which are always present in arid areas. A very thin layer of dust may decrease solar power conversion by $40 \%$.

The self-cleaning technology involves applying of a transparent, electrically sensitive material deposited on glass or a transparent plastic sheet covering the panels. Sensors monitor dust levels on the surface of the panel and energize the material when dust concentration reaches a critical level. The electric charge sends a dust-repelling wave cascading over the surface of the material, lifting away the dust and transporting it off of the screen's edges.

Within two minutes, the process removes about $90 \%$ of the dust deposited on a solar panel. [6]

\section{Conclusions}

The simulations performed in Comsol Multiphysics show the fact that when a cell is covered by a deposition, its internal temperature rises and thus it leads to occurrence of losses. The heating of cells by $10{ }^{\circ} \mathrm{C}$ was observed by experimental measurements, the effects of the covered area being showed by the thermo-vision camera. Thus, the studies on the behavior of photovoltaic cells covered by impurities show that these situations should be avoided as much as possible as inevitable losses occur in the system. Sometimes the losses can represent half or even more of the energy that should be produced by a system operating in normal conditions.
The way in which the photovoltaic panels that are affected by the deposits behave is very important especially when they are placed in locations where avoiding these deposits is impossible. Besides the automatic cleaning of the modules with specialized devices, covering them with layers that can reject the dust particles seems to be the most efficient and at hand solution until now.

\section{Acknowledgement}

This paper is supported by the Sectoral Operational Programme Human Resources Development (SOPHRD), financed from the European Social Fund and by the Romanian Government under the contract number POSDRU/88/1.5/S/61178.

\section{References}

[1] R.A. Messenger, J.Ventre,” Photovoltaic Systems Engineering", CRC Press, Florida 2004.

[2] G.Acciani, O.Falcone, S.Vergura, "Defects in poly-Silicon and amorphous Silicon solar cells", ICREPQ'10, Granada, Spain.

[3] R. Sullivan, "Shadow effects on a series-parallel array of solar cells", Greenbelt, Maryland, NASA article.

[4] F. Sick, Th. Erge, "Book for architects and engineers", UK 2003.

[5] G.Acciani, G.B. Simione, S.Vergura, "Thermographic Analysis of Photovoltaic Panels”, ICREPQ'10, Granada, Spain.

[6] M.K. Mazunder, 'Development of a Transparent SelfCleaning Dust Shield for Solar Panel, Particulate Science and Technology Journal", 25 (1), pp. 5-21.

[7] http://www.isfh.de/institut_solarforschung

[8] http://www.pvenlargement.com

[9] http://www.pveducation.org/pvcdrom

[10] D.Sera, Y. Baghzouz, "On the Impact of Partial Shading on PV Output Power', RES'08, Corfu, Greece. 